\title{
Changes in the Submandibular Gland in Patients with Head and Neck Cancer After Radiation Therapy: A Preliminary Study
}

\author{
YUKA UCHIYAMA ${ }^{1}$, SVEN KREIBORG ${ }^{1,2}$, SHUMEI MURAKAMI ${ }^{1,2,3}$, \\ TOMOMI TSUJIMOTO ${ }^{1}$ and IORI SUMIDA ${ }^{3}$ \\ ${ }^{1}$ Department of Oral and Maxillofacial Radiology, Osaka University Graduate School of Dentistry, Osaka, Japan; \\ ${ }^{2} 3$ Craniofacial Image Research Laboratory, University of Copenhagen, Copenhagen, Denmark; \\ ${ }^{3}$ Department of Radiation Oncology, Osaka University Graduate School of Medicine, Suita, Japan
}

\begin{abstract}
Aim: The purpose of this study was to assess the impairment of the submandibular gland, in terms of changes in volume by computed tomography $(C T)$ and $C T$ value, which was the mean pixel value at a region of interest, in a group of patients with head and neck cancer treated with radiation therapy (RT). Patients and Methods: Eleven patients treated with $R T$, where the effective radiation dose to the submandibular gland was known, were included in the study. CT scanning was performed both before and after RT. The average follow-up period after RT was 555 days (range $=107-1231$ days). Results: The mean volume of the submandibular gland decreased by around $38 \%(p<0.001)$ compared to the pre-treatment average until 600 days after $R T$. The mean $C T$ value of the submandibular gland decreased until 200 days after $R T(p<0.05)$. Conclusion: Both volume and $C T$ value of the submandibular gland showed signs of impairment of the gland during the first several months after RT for head and neck cancer.
\end{abstract}

Radiation therapy (RT) is an important treatment for patients with head and neck cancer because it better preserves form and function after treatment; and thereby a good quality of life for the majority of patients $(1,2)$. A common side-effect of RT in these patients is, however, impairment of the salivary glands, leading to xerostomia (3-7). In this context, several studies have reported a relationship between the radiation dose administered and the reduction of salivary production $(5,6,8,9)$. Furthermore, it has been shown that

Correspondence to: Yuka Uchiyama DDS, Ph.D., Department of Oral and Maxillofacial Radiology, Osaka University Graduate School of Dentistry, 1-8 Yamadaoka, Suita, Osaka 565-0871, Japan. Tel: +81 668792967, Fax: +81668792970, e-mail: momoka@dent.osakau.ac.jp

Key Words: Radiation therapy, head and neck cancer, submandibular gland, xerostomia.
RT in patients with head and neck cancer leads to shrinkage and deformation of irradiated salivary glands, and that the reduction in gland volume correlates significantly with the dose to the irradiated glands $(4,7,9)$.

Most studies on the impairment of salivary glands in patients received RT for head and neck cancer included targeted parotid glands $(7,9)$. It is well known, however, that in healthy individuals the submandibular glands produce the majority of saliva (60-65\%), whereas the parotid glands produce much less (20-30\%) (10).

The purpose of the present longitudinal study was to assess the impairment of the submandibular glands, in terms of changes in volume and CT value, in a group of patients with head and neck cancer treated with RT.

\section{Patients and Methods}

Patients. From 2000 to 2009, 233 patients with oral cancer were treated with RT at Osaka University Hospital. Patients who had undergone whole submandibular gland irradiation during treatment were selected for this study. All patients underwent unilateral neck dissection. No patient received chemotherapy during RT. The inclusion criteria were that $\mathrm{CT}$ scanning of the craniofacial region had been performed both before and after RT, and that the radiation dose to both the primary site and the submandibular glands was known. Eleven patients met the inclusion criteria; six males and five females; mean age 65 years (range $=30-88$ years) (see Table I). The study was approved by the Ethics Committee of our University (H21-E15-1), and written informed consent was obtained from all patients.

Radiation therapy. RT was performed with Linac ${ }^{\circledR}$ (Mitsubishi, Tokyo, Japan) using 4-MV X-rays. Portals were as follows: Single portal: the lateral single portal technique; double portal: the lateral double portal technique; triple portal: the lateral double portal technique combined with the field-in-field technique.

The total radiation dose to the primary tumor site was on average 55 Gy (range=50-62 Gy). The radiation dose to the submandibular gland was on average 46.4 Gy (range=33.1-63.7 Gy) (see Table I).

CT scanning. CT scanning was performed using Light Speed $\mathrm{QX} / \mathrm{i}^{\circledR}$ (GE Healthcare, Milwaukee, WI, USA). Scan conditions were as 
follows: $120 \mathrm{kVp}, 160$ or $200 \mathrm{~mA}, 512 \times 512$ matrix size, 2.5 or 5 $\mathrm{mm}$ slice thickness, and $\Phi 25 \mathrm{~cm}$ field of view. As mentioned above, CT scanning was performed both before and after RT in all patients. The average number of follow-up scans was three (range=2-4). The average follow-up period was 555 days (range=107-1231 days).

Measurements of submandibular glands. Gland volume: Using CT images without contrast enhancement, the gland volume was calculated with Analyze $4.0^{\circledR}$ (Mayo Clinic, Rochester, MN, USA). CT value: Using CT images without contrast enhancement, the $\mathrm{CT}$ value, i.e. the mean pixel value at a region of interest, was measured for set regions of interest of a submandibular gland at an irradiated site.

Evaluation. The follow-up period was classified into the following four time points: T1: $<60$ days after RT $(\mathrm{N}=11), \mathrm{T} 2$ : from 61 to 200 days after RT ( $\mathrm{N}=10), \mathrm{T} 3$ : from 201 to 600 days after $\mathrm{RT}(\mathrm{N}=9)$, and T4: $>600$ days after $\mathrm{RT}(\mathrm{N}=4)$. The change in volume and $\mathrm{CT}$ value was assessed and possible relations to radiation dose, age and gender were examined. As regards the radiation dose, the sample was divided into two groups: $\leq 45 \mathrm{~Gy}(\mathrm{~N}=6)$ and $>45 \mathrm{~Gy}(\mathrm{~N}=5)$. As regards age, the sample was divided in two groups: $\leq 65$ years $(\mathrm{N}=6)$ and $>65$ years $(\mathrm{N}=5)$. The mean radiation dose was $44 \mathrm{~Gy}$ and the mean age was 65 years. Thus the cut-off for radiation dose was $45 \mathrm{~Gy}$, which was considered the curative dose for head and neck cancer, and that for age was 65 years. The differences between mean values of both volume and $\mathrm{CT}$ value in the subgroups were tested statistically.

Statistical methods. Differences between mean values for volume and CT value were tested for significance using Student's $t$-test. The level of significance was set at $5 \%(p=0.05)$.

\section{Results}

Only 11 among 233 patients were periodically followed-up and underwent CT examinations completely.

Gland volume. Table II shows the volume of the submandibular gland at irradiated sites before treatment $(100 \%)$ and volumes as a percentage of the pre-treatment volume at the four follow-up time points after RT. The mean volume of the gland before treatment was $8964.7 \mathrm{~mm}^{3}$ (set as 100\%). At the first follow-up time point after RT (T1: until 60 days), the volume had decreased in all 11 patients, with mean volume decreasing to $77.7 \%$ (range=60.7-90.4\% $)(p<0.001)$ of the volume prior to RT. At the second follow-up time point (T2: 61-200 days), the mean volume was $71.6 \%$ (range $=54-$ $90.3 \%$ ). At the third follow-up time point (T3: 201-600 days), the mean volume had decreased to $62.3 \%$ (range $=43.6-77.4 \%)$ which was significantly less than at T1 $(p<0.05)$. The mean volume was unchanged $(62.6 \%)$ at the fourth follow-up time point (T4: over 600 days). However, only four patients completed the fourth examination, with an average total follow-up period of 1,100 days ( 3 years), and their individual curves for volume of the submandibular gland actually showed some recovery of volume at $\mathrm{T} 4$. The mean values for volume for these four patients at the four time points were: $\mathrm{T} 1=81.8 \% ; \mathrm{T} 2=62.8 \%$; $\mathrm{T} 3=54.5 \%$, and $\mathrm{T} 4=62.6 \%$.
In summary, the data showed a continuous decrease in volume of the submandibular glands at the irradiated sites of around 38\% until 600 days after RT; the most rapid decrease in volume occurring during the first 60 days after RT (22.3\%). After 600 days of follow-up, the mean volume stabilized. Signs of recovery of gland volume were observed in a few cases.

No statistically significant relations were observed for changes in volume of the submandibular gland as regards radiation dose ( $>45 \mathrm{~Gy} v s . \leq 45 \mathrm{~Gy}$ ), age ( $>65$ years of age $v s . \leq 65$ years of age), or gender.

CT value. Table III shows the relative CT values for the submandibular gland at the irradiated site after RT as a percentage of that prior to treatment. At the first follow-up time point after RT (T1: until 60 days), the mean CT value had decreased significantly to $86.2 \%$ (range $=58.1-115.0 \%$ ) $(p<0.05)$ compared to the value prior to RT; the CT value had decreased in nine patients and increased in two (case 3 and 4). At T2, the mean CT value had decreased further, but not significantly so, to $81.4 \%$. However, the CT value had in fact only decreased in six out of the 10 examined patients, whereas the value had increased somewhat in the four remaining patients. At T3, the mean CT value had increased slightly to 83.6\% (range=32.5-102.6\%). However, the CT value had markedly decreased (to $32.5 \%$ ) in one of the nine examined patients (case 4). When this outlier was omitted, the mean CT value for the remaining eight patients was $90 \%$. There was no significant difference. The mean CT value was $82.8 \%$ at T4.

However, only four patients had completed the fourth examination, and one of these was case 4 , still showing a very low $\mathrm{CT}$ value $(33.7 \%)$ compared to the other patients. When case 4 was omitted from the data, the mean CT value for the remaining three patients at $\mathrm{T} 4$ was $99.1 \%$ of the $\mathrm{CT}$ value prior to RT.

In summary, the change in CT value after RT was highly variable. However, the general finding was that the value decreased significantly by around $20 \%$ until 200 days after RT, and thereafter it stabilized or even showed signs of recovery towards the value prior to RT. A single case showed a deviant pattern, with an initial increase in CT value at $\mathrm{T} 1$ and thereafter a marked decrease at T3 and T4 of about $66 \%$ compared to the value prior to RT.

No statistically significant relations were observed for changes in CT value of the submandibular gland at the irradiated site as regards radiation dose ( $>45 \mathrm{~Gy} v s . \leq 45 \mathrm{~Gy})$, age ( $>65$ years of age $v s . \leq 65$ years of age), or gender.

\section{Discussion}

The observation of a statistically significant reduction in the volume of the submandibular gland after RT in patients with head and neck cancer is in accordance with the findings reported in two previous studies $(7,9)$. The most rapid 
Table I. Clinical characteristics of patients.

\begin{tabular}{|c|c|c|c|c|c|c|c|c|}
\hline \multirow[b]{2}{*}{ Case } & \multirow[b]{2}{*}{$\begin{array}{l}\text { Age } \\
\text { (years) }\end{array}$} & \multirow[b]{2}{*}{ Gender } & \multirow[b]{2}{*}{$\begin{array}{l}\text { Primary } \\
\text { site }\end{array}$} & \multirow[b]{2}{*}{$\begin{array}{l}\text { Radiation } \\
\text { site }\end{array}$} & \multicolumn{2}{|c|}{ RT dose (Gy) } & \multirow[b]{2}{*}{$\begin{array}{c}\text { Length of } \\
\text { follow-up (days) }\end{array}$} & \multirow[b]{2}{*}{$\begin{array}{c}\text { No. of CT } \\
\text { scans after RT }\end{array}$} \\
\hline & & & & & $\begin{array}{l}\text { Irradiated submandibular } \\
\text { gland }\end{array}$ & $\begin{array}{l}\text { Primary } \\
\text { site }\end{array}$ & & \\
\hline 1 & 54 & M & Lower mandible & Neck & 33.1 & 52 & 107 & 2 \\
\hline 2 & 69 & $\mathrm{~F}$ & Cheek & Neck & 34.7 & 50 & 370 & 3 \\
\hline 3 & 70 & M & Tongue & Neck & 39.8 & 50 & 1231 & 4 \\
\hline 4 & 58 & M & Tongue & Neck & 41.4 & 54 & 1064 & 4 \\
\hline 5 & 65 & $\mathrm{~F}$ & Cheek & Neck & 41.6 & 56 & 217 & 3 \\
\hline 6 & 30 & $\mathrm{~F}$ & Cheek & Primary & 44.0 & 58 & 1166 & 4 \\
\hline 7 & 77 & M & Lower mandible & Primary, neck & 47.2 & 56 & 292 & 3 \\
\hline 8 & 73 & $\mathrm{~F}$ & Soft palate & Primary & 52.3 & 62 & 936 & 3 \\
\hline 9 & 65 & $\mathrm{~F}$ & Tongue & Neck & 54.7 & 54 & 320 & 3 \\
\hline 10 & 88 & M & Lower mandible & Neck & 58.1 & 52 & 287 & 3 \\
\hline 11 & 61 & M & Lower mandible & Primary, neck & 63.7 & 62 & 110 & 2 \\
\hline Mean & 65 & & & & 46.4 & 55 & 555 & 3 \\
\hline
\end{tabular}

M: Male, F: female, CT: computed tomography, RT: radiotherapy.

Table II. Volume of submandibular gland of the irradiation field $\left(\mathrm{mm}^{3}\right)$ before radiotherapy $(R T)$ (set at 100.0\%) and relative volume after RT (\%) at different time points.

\begin{tabular}{|c|c|c|c|c|c|c|}
\hline \multirow[b]{2}{*}{ Case } & \multirow{2}{*}{$\begin{array}{l}\text { Volume of } \\
\text { submandibular } \\
\text { gland of the } \\
\text { irradiation } \\
\text { field range } \\
\text { before RT } \\
\left(\mathrm{mm}^{3}\right)\end{array}$} & \multicolumn{5}{|c|}{ Time point } \\
\hline & & $\begin{array}{c}\text { (before } \\
\text { RT) }\end{array}$ & $\begin{array}{l}(<60 \\
\text { days })\end{array}$ & $\begin{array}{c}(61- \\
200 \text { days })\end{array}$ & $\begin{array}{c}(201- \\
600 \text { days })\end{array}$ & $\begin{array}{l}(>600 \\
\text { days })\end{array}$ \\
\hline 1 & 6688.4 & 100 & 71.6 & 68.4 & - & - \\
\hline 2 & 7009.2 & 100 & 85.2 & 73.4 & 75.6 & - \\
\hline 3 & 9632.8 & 100 & 81.3 & 67.7 & 65.4 & 77.2 \\
\hline 4 & 11367.2 & 100 & 67.8 & 54.5 & 44.3 & 53.2 \\
\hline 5 & 8193.9 & 100 & 69.0 & 78.6 & 70.5 & - \\
\hline 6 & 10101.0 & 100 & 90.4 & 66.2 & 64.8 & 71.7 \\
\hline 7 & 8006.2 & 100 & 60.7 & 62.9 & 56.7 & - \\
\hline 8 & 10673.9 & 100 & 87.7 & - & 43.6 & 48.1 \\
\hline 9 & 9535.3 & 100 & 75.9 & 73.9 & 62.8 & - \\
\hline 10 & 9256.2 & 100 & 75.6 & 80.0 & 77.4 & - \\
\hline 11 & 8148.1 & 100 & 89.7 & 90.3 & - & - \\
\hline Mean & 8964.7 & 100 & 77.7 & 71.6 & 62.3 & 62.6 \\
\hline
\end{tabular}

volume loss $(22.3 \%)$ occurred during the initial period $(<60$ days) after RT. For comparison, Vásquez Osorio et al. reported a $20 \%$ volume loss of the submandibular gland 2 weeks after RT (9), and Wang et al. found a volume loss of $11.5 \%$ during the first 3 weeks of radiotherapy (7), finding no additional volume loss of the gland at 6-month follow-up. In contrast, the present study found that the loss of volume
Table III. Computed tomography (CT) value in the submandibular gland after radiotherapy $(R T)$ in percent of the value prior to treatment.

\begin{tabular}{lccccc}
\hline \multicolumn{5}{c}{ Time point } \\
\cline { 2 - 6 } Case & $\begin{array}{c}\text { Initial } \\
\text { (before }\end{array}$ & $\begin{array}{c}\text { T1 } \\
(<60 \\
\text { days })\end{array}$ & $\begin{array}{c}\text { T2 } \\
(61-200 \\
\text { days })\end{array}$ & $\begin{array}{c}\text { T3 } \\
(201-\end{array}$ & $\begin{array}{c}\text { T4 } \\
(>600 \\
\text { days })\end{array}$ \\
\hline 1 & 100 & 61.9 & 63.0 & - & - \\
2 & 100 & 81.2 & 78.0 & 82.7 & - \\
3 & 100 & 105.1 & 97.9 & 85.2 & 115.4 \\
4 & 100 & 115.0 & 87.5 & 32.5 & 33.7 \\
5 & 100 & 90.0 & 87.0 & 90.1 & - \\
6 & 100 & 99.7 & 98.4 & 102.6 & 99.7 \\
7 & 100 & 58.1 & 65.6 & 93.8 & - \\
8 & 100 & 95.7 & - & 81.9 & 82.2 \\
9 & 100 & 83.7 & 88.8 & 88.1 & - \\
10 & 100 & 80.6 & 61.5 & 95.4 & - \\
11 & 100 & 77.1 & 86.4 & - & - \\
Mean & 100 & 86.2 & 81.4 & 83.6 & 82.8 \\
\hline
\end{tabular}

seemed to continue, although at a slower pace, until 600 days after RT (7). Thereafter it seemed to stabilize and even show signs of recovery in a few cases at 3 -year follow-up. These differences may be explained by differences in study populations or treatment protocol. In the present study, the total average loss of volume of the submandibular gland at the irradiated site was around $38 \%$, and this probably contributes to xerostomia, which is a common side-effect in patients with head and neck cancer treated with RT (3-7). 
Assessment of xerostomia was, however, not performed for the patients included in the present study.

Wang et al. reported a significant positive correlation between the reduction in submandibular gland volume and the RT dose to the gland (7). The present study did not find such a relationship and nor did Vásquez Osorio et al. (9). The explanation for these differences could be differences in sample size in the three studies (Wang et al. (7) $\mathrm{N}=82$; Vásquez Osorio et al. (9) $\mathrm{N}=10$; present study $\mathrm{N}=11$ ).

Decrease in the CT value of the glands after RT means there is less vascular flow, and this could reflect impairment of the salivary gland tissue. An experimental study has shown that the microvascular endothelial cells in the salivary glands are damaged by RT and this leads to loss of salivary secretion (11). In the present study, the mean CT value in the submandibular gland decreased up until 200 days after RT, and thereafter it seemed to show signs of recovery. In a few cases, the CT value even returned to around the same level as that prior to RT. These findings would seem to be in agreement with the observations of Wang et al. who observed a statistically significant recovery of xerostomia grade over 3 to 6 months after RT (7). It is suggested that salivary gland tissue may start recovering about 6 months after RT.

In this study, 2D radiation technique not intensitymodulated RT was used. The purpose of this study was to determine the relationships between the radiation dose to the submandibular glands and their volume and CT value regardless of RT technique.

This study had several limitations. In order to assess the impairment of the submandibular gland after RT, in this study only patients with the whole submandibular gland irradiated during treatment were selected, therefore the study size was very small. The time of CT scanning was not uniform because the study was retrospective. Objective and subjective examinations were not performed. Moreover, the relationship between the change of submandibular gland volume and salivary function was not assessed.

\section{Conclusion}

We assessed the changes in the submandibular gland (in terms of volume and CT value) in patients with head and neck cancer after RT. The follow-up period was up to 3 years in several cases. For the volume, the mean decreased up to 600 days after RT (most rapidly during the first 60 days), and then stabilized or even showed signs of recovery. For the CT value, the mean value decreased up to 200 days after RT and then it gradually increased, probably as a sign of recovery of the gland tissue. On the basis of these data, we believe the function of irradiated submandibular gland is unlikely to be impaired 2 years after RT.

\section{References}

1 Harrison LB, Zelefsky MJ, Pfister DG, Carper E, Raben A, Kraus DH, Strong EW, Rao A, Thaler H, Polyak T and Portenoy $\mathrm{R}$ : Detailed quality of life assessment in patients treated with primary radiotherapy for squamous cell cancer of the base of the tongue. Head Neck 19(3): 169-175, 1997.

2 Robertson ML, Gleich LL, Barrett WL and Gluckman JL: Baseof-tongue cancer: survival, function, and quality of life after external-beam irradiation and brachytherapy. Laryngoscope 111(8): 1362-1365, 2001.

3 Almstahl A, Alstad T, Fagerberg-Mohlin B, Carlen A and Finizia C: Explorative study on quality of life in relation to salivary secretion rate in patients with head and neck cancer treated with radiotherapy. Head Neck 38: 782-791, 2016.

4 Barker JL Jr., Garden AS, Ang KK, O'Daniel JC, Wang H, Court LE, Morrison WH, Rosenthal DI, Chao KS, Tucker SL, Mohan $\mathrm{R}$ and Dong L: Quantification of volumetric and geometric changes occurring during fractionated radiotherapy for head-andneck cancer using an integrated CT/linear accelerator system. Int J Radiat Oncol Biol Phys 59(4): 960-970, 2004.

5 Anand AK, Jain J, Negi PS, Chaudhoory AR, Sinha SN, Choudhury PS, Kumar R and Munjal RK: Can dose reduction to one parotid gland prevent xerostomia? - A feasibility study for locally advanced head and neck cancer patients treated with intensity-modulated radiotherapy. Clin Oncol 18(6): 497-504, 2006.

6 Li Y, Taylor JM, Ten Haken RK and Eisbruch A: The impact of dose on parotid salivary recovery in head and neck cancer patients treated with radiation therapy. Int J Radiat Oncol Biol Phys 67(3): 660-669, 2007.

7 Wang ZH, Yan C, Zhang ZY, Zhang CP, Hu HS, Kirwan J and Mendenhall WM: Radiation-induced volume changes in parotid and submandibular glands in patients with head and neck cancer receiving postoperative radiotherapy: a longitudinal study. Laryngoscope 119(10): 1966-1974, 2009.

8 Amosson CM, Teh BS, Van TJ Uy N, Huang E, Mai WY, Frolov A, Woo SY, Chiu JK, Carpenter LS, Lu HH, Grant WH III and Butler EB: Dosimetric predictors of xerostomia for head-andneck cancer patients treated with the smart (simultaneous modulated accelerated radiation therapy) boost technique. Int $\mathbf{J}$ Radiat Oncol Biol Phys 56(1): 136-144, 2003.

9 Vásquez Osorio EM, Hoogeman MS, Al-Mamgani A, Teguh DN, Levendag PC and Heijmen BJ: Local anatomic changes in parotid and submandibular glands during radiotherapy for oropharynx cancer and correlation with dose, studied in detail with nonrigid registration. Int J Radiat Oncol Biol Phys 70(3): 875-882, 2008.

10 Schneyer LH and Levin LK: Rate of secretion by exogenously stimulated salivary gland pairs of man. J Appl Physiol 7: 609613, 1955.

11 Cotrim AP, Sowers A, Mitchell JB and Baum BJ: Prevention of irradiation-induced salivary hypofunction by microvessel protection in mouse salivary glands. Mol Ther 15: 2101-2106, 2007. 